\title{
Opioid use disorder is associated with increased mortality and morbidity in patients with gastroparesis
}

\author{
Mohamed Tausif Siddiquia, Mohammad Bilal ${ }^{b}$, Beth Schorr-Lesnickc, Edward Lebovicsc, Brad Dworkin ${ }^{c}$
}

New York Medical College, Valhalla, NY; University of Texas Medical Branch, Galveston, TX, USA

Abstract

Background Opioid use disorder (OUD) epidemic has been declared a nationwide public health emergency by the Department of Health and Human Services. There are limited data regarding OUD in patients with gastroparesis. This study aimed to evaluate the impact of OUD on the outcomes in patients hospitalized with gastroparesis and to delineate the trends associated with OUD and gastroparesis using a nationally representative sample.

Methods We used the National (Nationwide) Inpatient Sample database from 2005-2014 to identify patients hospitalized with a primary diagnosis of gastroparesis (ICD 9 Code: 536.3 ) and a concurrent diagnosis of OUD. We used Pearson chi-square analysis to compare demographics, the independent samples t-test to assess differences in length of stay and cost of care, and multivariate regression analysis to adjust for confounders.

Results Between 2005 and 2014, a total of 145,700 patients with a primary diagnosis of gastroparesis were hospitalized in the United States, of whom 4519 (3.1\%) had a concurrent diagnosis of OUD. The prevalence of OUD in gastroparesis doubled from $2.1 \%$ in 2005 to $4.3 \%$ in 2014. After adjusting for confounders, patients with OUD had greater in-hospital mortality (adjusted odds ratio 2.7, 95\% confidence interval: 2.1-3.5). Patients with OUD also had significantly longer hospital stays and higher costs. Independent predictors of OUD in patients with gastroparesis were younger age, female sex, alcohol use, depression, and Medicaid insurance.

Conclusion OUD in patients with gastroparesis is associated with greater mortality and healthcare resource utilization.

Keywords Gastroparesis, opioid use disorder, healthcare cost and utilization project, national inpatient sample database

Ann Gastroenterol 2019; 32 (4): 1-8

\section{Introduction}

Gastroparesis is a complex neuromuscular disorder characterized by delayed gastric emptying $[1,2]$. The condition can cause a wide variety of symptoms, such as nausea, vomiting, bloating, early satiety, postprandial fullness, and chronic

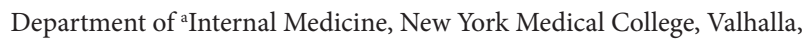
NY (Mohamed Tausif Siddiqui); ' Gastroenterology, University of Texas Medical Branch, Galveston, TX (Mohammad Bilal); Department of ${ }^{\mathrm{c}}$ Gastroenterology, New York Medical College, Valhalla, NY (Beth Schorr-Lesnick, Edward Lebovics, Brad Dworkin), USA

\section{Conflict of Interest: None}

Correspondence to: MohamedTausif Siddiqui, MD, 100 Woods Road Suite D-322, Valhalla NY 10595, USA, e-mail: dr_tausifsiddiqui@ yahoo.com; tausif_siddiqui@nymc.edu

Received 14 February 2019; accepted 23 April 2019; published online 22 May 2019

DOI: https://doi.org/10.20524/aog.2019.0389 abdominal pain [3]. Chronic abdominal pain is often challenging to manage and hence opioid use is becoming common among patients with diabetic and idiopathic gastroparesis [4,5]. Previous studies have reported that $30-43 \%$ of gastroparesis patients are on chronic opioids [4-7]. Opioids provide immediate pain relief but can lead to other gastrointestinal side effects, such as nausea, vomiting, constipation, gastroesophageal reflux disease, and worsening of gastric emptying. This in turn leads to worsening of gastroparesis thereby turning it into a vicious cycle. However, these adverse effects are often overlooked when opioids are prescribed to these patients [4]. Many patients with chronic opioid use develop chronic abdominal pain and narcotic bowel syndrome [8]. In view of the increasing use of opioids and resulting opioid-induced gastroparesis, several studies are currently investigating alternative therapeutic options [9].

The United States is currently in the midst of an opioid crisis and the opioid epidemic has been declared a public health emergency [10-12]. The continuing rise in the prevalence of OUD has led to a concurrent increase in opioidrelated complications, associated deaths and the burden on 
healthcare resources $[11,13]$. According to a report from the US Department of Health and Human Services, in 2016 about 11.5 million Americans were misusing prescription opioids, while 2.1 million had OUD and more than 42,000 died from an opioid overdose $[14,15]$. Up to one third of the patients in whom opioids were prescribed reported misusing them and approx. $12 \%$ transition to developing OUD [16]. The Centers for Disease Control and Prevention (CDC) estimated the total economic burden of prescription opioid misuse in the United States to be 78.5 billion dollars a year [17]. In April 2018, to address this national crisis, the US Department of Health and Human Services launched an initiative with the National Institute of Health called "Helping to End Addiction Long-term (HEAL)", to improve the treatment of opioid misuse and for exploration of alternative therapies in chronic pain management [18].

Even though the use of opioids in gastroparesis is increasing, there continues to be a paucity of literature regarding the impact of OUD on outcomes in patients with gastroparesis. In the current study we aimed to evaluate the impact of OUD on the outcomes of patients hospitalized with gastroparesis and to delineate the trends associated with OUD and gastroparesis using a nationally representative sample.

\section{Patients and methods}

\section{Data source}

We used the National (Nationwide) Inpatient Sample (NIS) database from 2005-2014. The NIS database is developed and maintained by the Healthcare Cost and Utilization Project (HCUP) and is utilized in decision making at national and community levels. It is the largest publicly available all-payer inpatient healthcare database in the United States. The HCUP is an initiative of the Agency for Healthcare Research and Quality. The NIS database contains de-identified data for more than 7 million unweighted annual hospital stays and 35 million weighted annual US hospitalization records. From 2005-2014, NIS included between 7 and 8 million discharges yearly from 1051-4411 hospitals in 37-45 states across the US [19].

The NIS is the nation's most comprehensive source of hospital data, which enables researchers to study healthcare delivery and patient outcomes. It is a discharge-level database that contains de-identified clinical and nonclinical data elements at both the patient and hospital-level. As a result, multiple admissions for a single patient are considered separate discharges and are entered separately in the database. Patientlevel data points include age, sex, race, income in the patient's zip code, and principal diagnosis, plus up to 29 secondary diagnoses, using the International Classification of Diseases, $9^{\text {th }}$ Revision, Clinical Modification (ICD9-CM) coding system, as well as up to 15 procedures using the ICD-9 CM procedural codes. Hospital-level data include hospital teaching status, number of beds, and hospital location (urban/rural). The NIS also contains information regarding discharge disposition, including death and resource utilization, length of hospital stay, and total hospitalization charges.

\section{Study population}

Patients included in the study were those with a principal diagnosis of gastroparesis (ICD-9 CM code 536.3). Patients were excluded if they were less than 18 years of age. Patients with concomitant OUD were then identified. The ICD-9 CM coding system does not have a unique code for OUD; therefore, we reviewed previously published manuscripts on the topic and identified a reliable algorithm to identify patients with OUD $[12,13,20,21]$. We also followed the guidelines published in the HCUP statistical brief to identify the cases with OUD. The ICD-9-CM diagnostic codes used to identify cases with gastroparesis and OUD are listed in the Table 1.

\section{Study outcomes and variables}

The primary outcome measure was in-hospital mortality. Secondary outcomes were: i) the prevalence and annual trends in OUD among patients hospitalized with gastroparesis; ii) resource utilization, as measured by length of hospital stay and total hospitalization charges and costs; and iii) independent predictors associated with OUD in gastroparesis patients. Multiple potential confounders were collected and accounted for during the analysis, including age, sex, race, NIS severity subclass, mortality risk subclass, comorbidities with Elixhauser comorbidity index, number of procedures, insurance status and primary payer, and hospital factors including region, bed number, hospital location, and teaching status.

Length of hospital stay, total hospitalization charges and patients' demographics were directly obtained from the NIS database. The HCUP provides data that contain hospitalspecific cost-to-charge ratios based on all-payer inpatient cost. All hospitalization costs were adjusted for inflation over the years using the consumer price index and presented in 2014 US dollars. Comorbidity burden was assessed using Elixhauser's comorbidity index [22].

Table 1 ICD 9 CM codes

\begin{tabular}{|c|c|}
\hline \multicolumn{2}{|c|}{ Opioids use disorder ICD codes } \\
\hline $304.00-304.03$ & Opioid type dependence \\
\hline $304.70-304.73$ & $\begin{array}{l}\text { Combinations of opioids with any other } \\
\text { drug dependence }\end{array}$ \\
\hline $305.50-305.53$ & Nondependent opioid abuse \\
\hline 965.00 & Poisoning by opium \\
\hline 965.01 & Poisoning by heroin \\
\hline 965.02 & Poisoning by methadone \\
\hline 965.09 & $\begin{array}{l}\text { Poisoning by other opiates and related } \\
\text { narcotics }\end{array}$ \\
\hline E850.0-E850.2 & $\begin{array}{l}\text { Accidental poisoning by heroin; methadone; } \\
\text { other opiates and related narcotics }\end{array}$ \\
\hline E935.0 & Heroin, adverse effects \\
\hline
\end{tabular}




\section{Statistical analysis}

All statistical analyses were performed using the SPSS Statistical software v25.0 (IBM corp., Chicago, Illinois). A bivariate analysis with Pearson's chi-squared test was used to compare the demographics, covariates and outcomes of interest among the study groups. Two-sided P-values were reported and a value less than 0.05 was considered to be statistically significant. We used a multivariate logistic regression model to adjust for the pertinent demographic variables and confounders. For the primary outcome, a logistic regression model was used to compare inhospital mortality between OUD and non-OUD patients. The HCUP comorbidity software was used to generate Elixhauser comorbidities from ICD-9 CM diagnosis codes. We adjusted for age, sex, race, insurance status, comorbidities, disease severity index and Elixhauser comorbidity index. We used a general linear model and performed multivariate analysis to calculate adjusted mean differences in length of stay and cost of hospital care.

\section{Results}

\section{Patient and hospital characteristics}

A total of 145,700 hospitalizations with gastroparesis were included in our analysis (Fig. 1). Of these, 4519 (3.1\%) patients also had OUD. The mean age of the study cohort was 46.9 years and $73.6 \%$ were female. The majority of the patients were Caucasians $(67.2 \%)$, were cared for at hospitals with a large number of beds $(64.1 \%)$, were admitted to an urban teaching hospital (51.4\%), and were weekday admissions (77.8\%); 40.1\% of the patients had Medicare insurance. Patient demographics have been summarized in Table 2 .

\section{Prevalence and trends of OUD in hospitalized gastroparesis patients}

From 2005-2014, total gastroparesis-related hospitalizations increased by $59 \%$, from 9924 to 15,865 (Table 3). During the same period, the prevalence of OUD in gastroparesis patients increased by $227 \%$, from 209 to 685 . The percentage of gastroparesis patients with OUD doubled between 2005 (2.1\%) and 2014 (4.3\%). Fig. 2 shows a graphical representation of the changes over that decade.

\section{In-hospital mortality}

The overall mortality rate of the entire cohort was 4 deaths per 1000 hospital admissions. The unadjusted mortality rate in patients with gastroparesis and OUD was $0.2 \%$, while it was $0.4 \%$ in patients without OUD. However, gastroparesis patients with OUD were significantly younger than those without. We then performed a multivariate regression analysis, adjusting for all potential confounders outlined in the Methods section. After adjusting for confounders, patients with OUD had significantly greater mortality compared to patients without

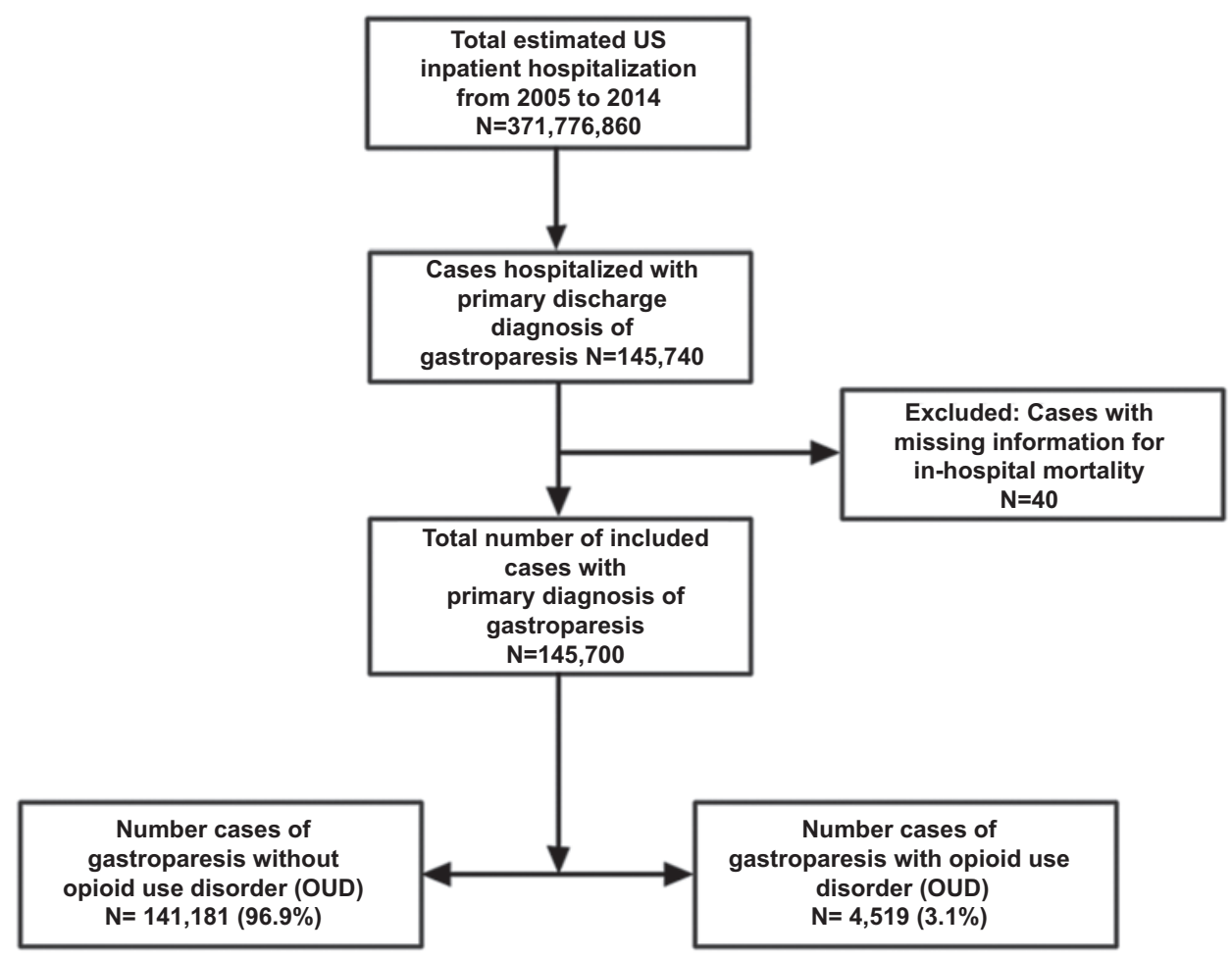

Figure 1 Flowchart presenting algorithm of case selection and exclusion 
Table 2 Demographic characteristics of cases with gastroparesis and opioid use disorder (OUD)

\begin{tabular}{|c|c|c|c|c|}
\hline \multirow[t]{2}{*}{ Baseline characteristic } & & \multicolumn{2}{|c|}{ OUD } & \multirow[t]{2}{*}{ P-value } \\
\hline & & $\begin{array}{c}\text { No } \\
\mathrm{N}=141,181(96.9 \%)\end{array}$ & $\begin{array}{c}\text { Yes } \\
\mathrm{N}=4519(3.1 \%)\end{array}$ & \\
\hline Age (years) & Mean (SD) & 49.93 (SD 17.35) & $43.14(\mathrm{SD} 12.24)$ & $\mathrm{P}<0.001$ \\
\hline \multirow[t]{4}{*}{ Age group } & $18-35$ & $32377(22.9 \%)$ & $1347(29.8 \%)$ & $\mathrm{P}<0.001$ \\
\hline & $36-50$ & $44562(31.6 \%)$ & $1882(41.6 \%)$ & \\
\hline & $51-65$ & $35612(25.2 \%)$ & $1102(24.4 \%)$ & \\
\hline & $>65$ & $28630(20.3 \%)$ & $188(4.2 \%)$ & \\
\hline \multirow[t]{2}{*}{ Sex } & Male & $37511(26.6 \%)$ & $896(19.8 \%)$ & $\mathrm{P}<0.001$ \\
\hline & Female & $103670(73.4 \%)$ & $3623(80.2 \%)$ & \\
\hline \multirow[t]{6}{*}{ Race } & White & $94,688(67.1 \%)$ & $3159(69.9 \%)$ & $\mathrm{P}<0.001$ \\
\hline & Black & 30637 (21.7\%) & $890(19.7 \%)$ & \\
\hline & Hispanic & $11216(7.9 \%)$ & $290(6.4 \%)$ & \\
\hline & Asian or Pacific islander & $1354(1.0 \%)$ & $45(1.0 \%)$ & \\
\hline & Native American & $720(0.5 \%)$ & $24(0.5 \%)$ & \\
\hline & Other & $2566(1.8 \%)$ & $111(2.5 \%)$ & \\
\hline \multirow{6}{*}{$\begin{array}{l}\text { Insurance status: } \\
\text { Primary expected payer }\end{array}$} & Medicare & $56930(40.3 \%)$ & $1485(32.9 \%)$ & $\mathrm{P}<0.001$ \\
\hline & Medicaid & $23967(17.0 \%)$ & $1207(26.7 \%)$ & \\
\hline & Private insurance & $47128(33.4 \%)$ & $1346(29.8 \%)$ & \\
\hline & Self-pay & $8109(5.7 \%)$ & $263(5.8 \%)$ & \\
\hline & No charge & $953(0.7 \%)$ & $44(1.0 \%)$ & \\
\hline & Other & $4094(2.9 \%)$ & $174(3.8 \%)$ & \\
\hline \multirow[t]{4}{*}{ Region of hospital } & Northeast & $22967(16.3 \%)$ & $838(18.5 \%)$ & $\mathrm{P}<0.001$ \\
\hline & Midwest & $29525(20.9 \%)$ & $637(14.1 \%)$ & \\
\hline & South & $67206(47.6 \%)$ & $1844(40.8 \%)$ & \\
\hline & West & $21483(15.2 \%)$ & $1200(26.6 \%)$ & \\
\hline \multirow[t]{3}{*}{ Hospital number of beds (STRATA) } & Small & $15426(10.9 \%)$ & $521(11.5 \%)$ & $\mathrm{P}=0.155$ \\
\hline & Medium & $35233(25.0 \%)$ & $1162(25.7 \%)$ & \\
\hline & Large & $90522(64.1 \%)$ & $2836(62.8 \%)$ & \\
\hline \multirow[t]{3}{*}{ Location/teaching status of hospital (STRATA) } & Rural & $13293(9.4 \%)$ & $223(4.9 \%)$ & $\mathrm{P}<0.001$ \\
\hline & Urban non-teaching & $55530(39.3 \%)$ & $1815(40.2 \%)$ & \\
\hline & Urban teaching & $72358(51.3 \%)$ & $2481(54.9 \%)$ & \\
\hline
\end{tabular}

OUD: adjusted odds ratio $2.7,95 \%$ confidence interval (CI) 2.17-3.58, $\mathrm{P}<0.001$ (Table 4).

\section{Healthcare resource utilization}

The mean length of stay was longer in patients with OUD (5.8 days) than in those without (5.1 days) (Table 4). After adjustment for confounders, gastroparesis patients with OUD were associated with a hospital stay 1.5 days longer compared to other gastroparesis patients (95\%CI 1.3-1.7, $\mathrm{P}<0.001)$.

The mean total hospitalization costs were also higher for patients with gastroparesis and OUD (\$9338) than for those without OUD (\$8336). Patients with OUD and gastroparesis had significantly higher total hospitalization costs, according to multivariate regression analysis to adjust for confounders. The mean adjusted difference in total hospitalization costs was \$2077 (95\%CI \$1788-2365, P<0.001).

\section{Independent predictors for OUD in patients with gastroparesis}

Table 5 shows the independent predictors for OUD in patients with gastroparesis. The strength of association for OUD was tested using multivariate regression analysis. The 


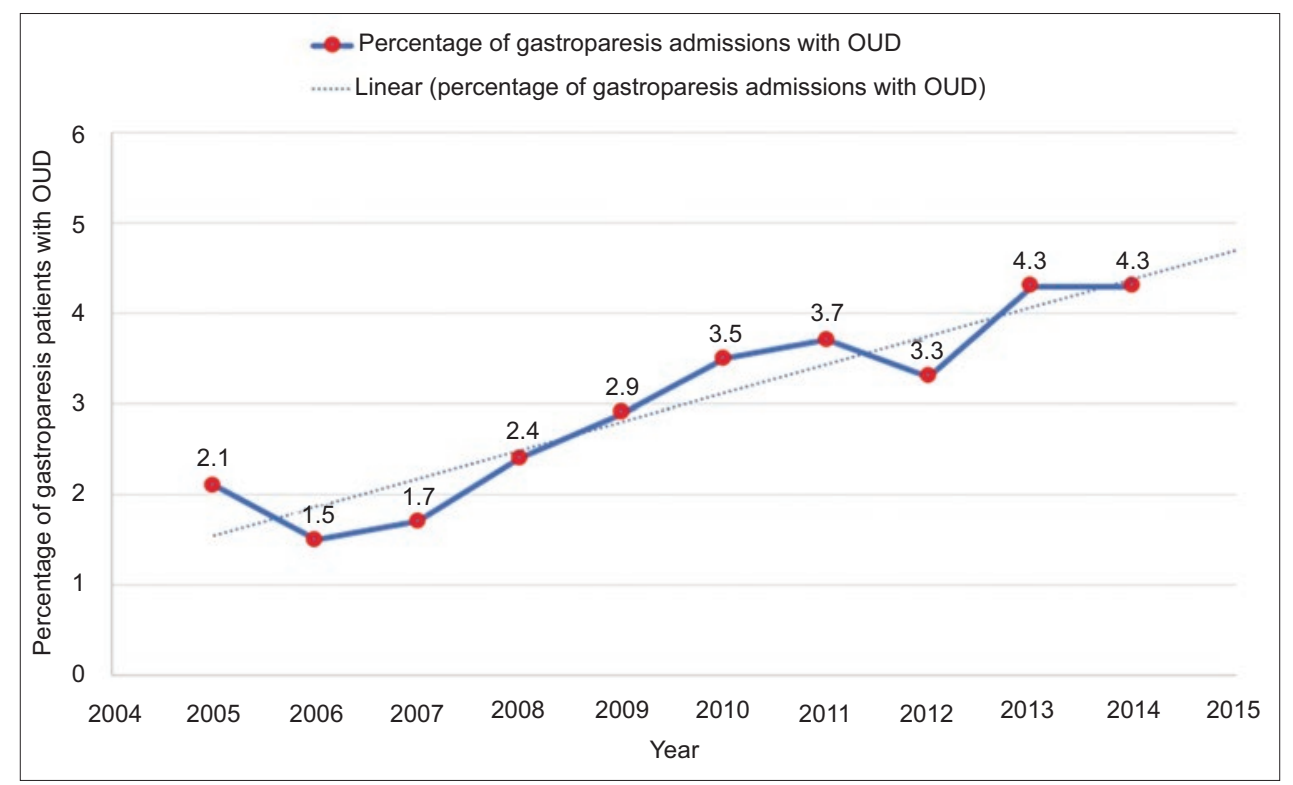

Figure 2 Time graph presenting opioid use disorder (OUD) trend in hospitalized patients with gastroparesis

Table 3 Yearly trend of gastroparesis admissions with and without opioid use disorder (OUD)

\begin{tabular}{lccc}
\hline Year & $\begin{array}{c}\text { Total gastroparesis } \\
\text { hospitalizations }\end{array}$ & $\begin{array}{c}\text { Gastroparesis } \\
\text { hospitalizations with OUD }\end{array}$ & $\begin{array}{c}\text { Percentage of gastroparesis } \\
\text { hospitalization with OUD (\%) }\end{array}$ \\
\hline 2005 & 9924 & 209 & 2.1 \\
2006 & 11,780 & 171 & 1.5 \\
2007 & 11,931 & 199 & 1.7 \\
2008 & 13,929 & 340 & 2.4 \\
2009 & 15,588 & 458 & 2.9 \\
2010 & 17,263 & 597 & 3.5 \\
2011 & 17,219 & 629 & 3.7 \\
2012 & 16,530 & 550 & 3.3 \\
2013 & 15,671 & 681 & 4.3 \\
\hline 2014 & 15,865 & 685 & 4.3 \\
\hline
\end{tabular}

Table 4 Comparison of outcome and cost of admissions between patients with opioid use disorder (OUD) and non-OUD patients

\begin{tabular}{lccc}
\hline Outcome & Non-OUD $(\mathrm{n}=141,181) \mathrm{n}(\%)$ & OUD $(\mathrm{n}=4519) \mathrm{n}(\%)$ & Total $(\mathrm{N}=145,700)$ \\
\hline In-hospital mortality & $587(0.4 \%)$ & $11(0.2 \%)$ & $\mathrm{P}=0.074$ \\
Mean length of stay (SD) & $5.14( \pm 5.2)$ & $5.81( \pm 5.90)$ & $\mathrm{P}<0.0001$ \\
Mean hospitalization cost & $\$ 8336$ & $\$ 9338$ & $\mathrm{P}<0.0001$ \\
\hline SD, standard deviation & &
\end{tabular}

$\overline{S D}$, standard deviation

variables used have been outlined in the Methods section. The variables found to independently increase the odds of OUD in gastroparesis patients were younger age, female sex, Medicaid insurance, concurrent alcohol use, and depression. Gastroparesis patients with more severe illness, those presenting to urban hospitals and weekend admissions were also more likely to have OUD.

\section{Discussion}

We used the largest inpatient all-payer database to evaluate the impact of opioid use diagnosis on patients hospitalized with gastroparesis. To the best of our knowledge, this is the first study to analyze the impact of OUD among gastroparesis patients on a national scale. We found a steady increase in 
Table 5 Multinomial logistic regression analysis of factors associated with opioid use disorder (OUD) in cases admitted with a primary diagnosis of gastroparesis

\begin{tabular}{|c|c|c|c|c|c|}
\hline \multirow[t]{2}{*}{ Variable } & & \multirow[t]{2}{*}{ Adjusted odds ratio } & \multicolumn{2}{|c|}{$\begin{array}{c}\text { 95\% confidence interval for } \\
\text { adjusted-OR }\end{array}$} & \multirow[t]{2}{*}{$\mathrm{P}$-value } \\
\hline & & & Lower limit & Upper limit & \\
\hline \multirow[t]{4}{*}{ Age groups } & $18-35$ & 6.066 & 5.141 & 7.157 & $\mathrm{P}<0.001$ \\
\hline & $36-50$ & 5.906 & 5.031 & 6.933 & $\mathrm{P}<0.001$ \\
\hline & $51-65$ & 4.416 & 3.756 & 5.192 & $\mathrm{P}<0.001$ \\
\hline & $>65$ & $\mathrm{R}$ & - & - & - \\
\hline \multirow[t]{2}{*}{ Sex } & Male & 0.773 & 0.716 & 0.834 & $\mathrm{P}<0.001$ \\
\hline & Female & $\mathrm{R}$ & - & - & \\
\hline \multirow[t]{5}{*}{ Race } & White & $\mathrm{R}$ & - & - & - \\
\hline & Black & 0.833 & 0.758 & 0.915 & $\mathrm{P}<0.001$ \\
\hline & Hispanic & 0.786 & 0.681 & 0.907 & $\mathrm{P}=0.001$ \\
\hline & Asian or Pacific Islander & 0.963 & 0.599 & 1.548 & $\mathrm{P}=0.870$ \\
\hline & Native American & 0.782 & 0.397 & 1.295 & $\mathrm{P}=0.335$ \\
\hline \multirow[t]{2}{*}{ Alcohol use } & Yes & 1.283 & 1.075 & 1.531 & $\mathrm{P}=0.006$ \\
\hline & No & $\mathrm{R}$ & - & - & - \\
\hline \multirow[t]{2}{*}{ Depression } & Yes & 1.383 & 1.293 & 1.479 & $\mathrm{P}<0.001$ \\
\hline & No & $\mathrm{R}$ & - & - & - \\
\hline \multirow[t]{2}{*}{ Weekend admission } & Yes & 1.223 & 1.141 & 1.310 & $\mathrm{P}<0.001$ \\
\hline & No & $\mathrm{R}$ & - & - & - \\
\hline \multicolumn{6}{|c|}{ All patient refined DRG: Severity of illness subclass } \\
\hline Severity of illness subclass $=1$ & Minor & 0.249 & 0.192 & 0.322 & $\mathrm{P}<0.001$ \\
\hline Severity of illness subclass $=2$ & Moderate & 0.517 & 0.405 & 0.660 & $\mathrm{P}<0.001$ \\
\hline Severity of illness subclass $=3$ & Major & 0.861 & 0.681 & 1.089 & $\mathrm{P}=0.213$ \\
\hline Severity of illness subclass $=4$ & Extreme & $\mathrm{R}$ & - & - & - \\
\hline \multirow[t]{3}{*}{ Location/teaching status of hospital } & Rural & 0.556 & 0.482 & 0.642 & $\mathrm{P}<0.001$ \\
\hline & Urban Non-Teaching & 1.008 & 0.946 & 1.074 & $\mathrm{P}=0.811$ \\
\hline & Urban Teaching & $\mathrm{R}$ & - & - & - \\
\hline \multirow[t]{6}{*}{ Primary expected payer } & Medicare & $\mathrm{R}$ & - & - & - \\
\hline & Medicaid & 1.170 & 1.077 & 1.272 & $\mathrm{P}<0.001$ \\
\hline & Private Insurance & 0.664 & 0.614 & 0.720 & $\mathrm{P}<0.001$ \\
\hline & Self-pay & 0.803 & 0.699 & 0.922 & $\mathrm{P}=0.002$ \\
\hline & No charge & 1.108 & 0.813 & 1.511 & $\mathrm{P}=0.516$ \\
\hline & Others & 1.047 & 0.888 & 1.233 & $\mathrm{P}=0.587$ \\
\hline
\end{tabular}

$\overline{D R G}$, diagnosis-related group; $R$, Reference category

the prevalence of OUD in hospitalized gastroparesis patients over the last decade. In addition, patients with gastroparesis and OUD had significantly higher mortality and increased healthcare resource utilization, measured by length of hospital stay, and total hospitalization costs.

Our study confirms the previously reported trend of an increase in OUD prevalence in various other hospitalized populations $[4,12,13]$. Weiss et al previously analyzed the national inpatient sample database and published their findings in the HCUP statistical brief [12]. They reported an overall increase in the prevalence of OUD hospitalizations by $64.1 \%$ over the last decade [12]. We found this increase in the prevalence of OUD to be $227 \%$ in gastroparesis patients, 3-4 times higher than other hospitalizations. Another study analyzing the prevalence of OUD in patients hospitalized for inflammatory bowel disease reported an $88 \%$ increase in the prevalence of OUD over the past decade [13]. Since the prevalence of OUD in gastroparesis patients is increasing much faster than that of other disorders, 
these patients are likely to continue to be more vulnerable to OUD-related complications in coming years. This increase is probably related to the overall increase in OUD. Patients with gastroparesis usually have chronic abdominal pain and are more likely to end up on opioid therapy.

According to our study, OUD not only increases the risk of in-hospital mortality, but it also significantly increases the length of hospital stay and the overall cost of care, thus adding to the overall national healthcare burden. The impact on mortality and healthcare resource utilization persisted even after adjustment for potential confounders. These findings are consistent with the impact of OUD on other chronic disease [13]. A possible reason is that patients who have OUD are perhaps more likely to get intravenous narcotics on admission to the hospital. It then takes longer to transition them back to oral opioids before discharge, compared to those without OUD. This results in a prolonged hospital stay and in turn an increase in hospitalization costs. In addition, chronic opioid use has been reported to be associated with poor quality of life in previous survey-based studies [23]. Gastroparesis patients who are chronically on opioids are more likely to be unemployed and work less [4]. More than 130 daily deaths result from opioid-related complications and the overall economic burden of opioid disorder is significantly high. The White House Council of Economic Advisers estimated that the cost of opioid-involved overdose deaths in 2015 was $\$ 549$ billion [24-26]. The CDC and Department of Health and Human Services have implemented various measures to curb the health care and economic burden of the OUD.

We also found that younger patients with gastroparesis were more likely to have OUD, as were females and patients with Medicaid insurance. Our finding in the gastroparesis cohort is consistent with a CDC report that showed a 4-fold increase in OUD during labor and delivery; safety measures have since been introduced to limit the maternal and neonatal complication rate $[27,28]$. This emphasizes the need for special attention to gastroparesis management for women of childbearing age. Caution should be observed and alternative therapy should be sought in such cases. OUD in gastroparesis patients appears to be more of an urban phenomenon, with a much higher prevalence in urban hospitals, both teaching and non-teaching. Behavioral pattern also appears to play an important role in the development of OUD. Our multivariate analysis also found alcohol use and depression to be independent predictors of OUD in patients with gastroparesis. Likewise, alcohol use and depression increased the risk of OUD in gastroparesis patients. Previous reports have suggested that patients with underlying psychiatric illnesses have a higher perception of pain [29]. This is possibly why these patients are more likely to end up on chronic opioid therapy.

Adequate pain control is very important in the management of gastroparesis. However, the use of opioids in these patient populations is fraught with extensive disadvantages, including worsening of gastroparesis symptoms, failure of implanted pacemakers, labor- and delivery-related complications, increased mortality, and increased overall healthcare expenditure [7,23]. Gastroparesis patients are at particularly higher risk for these complications. Hence, efforts should be made to seek alternative pain management modalities for these patients.
Our study has several limitations. It was a large database observational study, which does not allow for individual chart reviews. We were unable to assess the severity of pain for each individual hospitalization or the specific indication for opioids. We could not differentiate whether the opioids in these patients were used for the gastroparesis-related abdominal pain, or whether the gastroparesis was a manifestation of opioid use. Moreover, our data were obtained from an administrative database. It has been documented that claims-based databases are susceptible to inaccurately entered or missing codes [30]. However, ICD-9 CM codes have been shown to have a high specificity and sensitivity when used to study gastrointestinal diseases [31]. The NIS database also does not allow us to identify the etiology of gastroparesis (diabetic, idiopathic, etc.) and hence we cannot differentiate the impact of OUD on gastroparesis with different etiologies. Lastly, since our study was retrospective, the study population was not randomized. Even though we used a robust statistical analysis to adjust for confounding factors, there is still a risk of residual confounding.

Despite these limitations, our study has several strengths. It is the first to evaluate the extent and impact of the opioid epidemic on patients with gastroparesis. It used the largest publicly available inpatient national database. The use of such a database minimizes the biases seen in single-center or even smaller multicenter studies. This makes the results more generalizable across the country. With increasing opioid dependence in the US and strenuous efforts by the Government to curb the use of opioids, this analysis is both timely and warranted for gastroparesis patients.

In conclusion, the prevalence of OUD is increasing in patients with gastroparesis. OUD was associated with relatively higher mortality and increased health care utilization in hospitalized gastroparesis patients. Gastroenterologists need to be cautious about using opioids in patients with gastroparesis and alternative pain management modalities should be preferred in these patients. Further large prospective studies are needed to validate our findings.

\section{Summary Box}

\section{What is already known:}

- The opioid epidemic has been declared as a public health emergency in the United States

- Opioids are often used for managing pain in patients with gastroparesis

\section{What the new findings are:}

- There has been an increase in the prevalence of opioid use disorder in hospitalized gastroparesis patients over the last decade

- Patients with gastroparesis and opioid use disorder had relatively higher mortality and consumed more healthcare resources than did those with no opioid use 


\section{References}

1. Khoo J, Rayner CK, Jones KL, Horowitz M. Pathophysiology and management of gastroparesis. Expert Rev Gastroenterol Hepatol 2009;3:167-181.

2. Tack J, Carbone F, Rotondo A. Gastroparesis. Curr Opin Gastroenterol 2015;31:499-505.

3. Revicki DA, Rentz AM, Dubois D, et al. Gastroparesis Cardinal Symptom Index (GCSI): development and validation of a patient reported assessment of severity of gastroparesis symptoms. Qual Life Res 2004;13:833-844.

4. Jehangir A, Parkman HP. Chronic opioids in gastroparesis: relationship with gastrointestinal symptoms, healthcare utilization and employment. World J Gastroenterol 2017;23:7310-7320.

5. Camilleri M, Parkman HP, Shafi MA, Abell TL, Gerson L; American College of Gastroenterology. Clinical guideline: management of gastroparesis. Am J Gastroenterol 2013;108:18-37.

6. Bielefeldt K, Raza N, Zickmund SL. Different faces of gastroparesis. World J Gastroenterol 2009;15:6052-6060.

7. Hasler WL, Wilson LA, Nguyen LA, et al; Gastroparesis Clinical Research Consortium. Opioid use and potency are associated with clinical features, quality of life, and use of resources in patients with gastroparesis. Clin Gastroenterol Hepatol 2018 Oct 13 [Epub ahead of print]. doi: 10.1016/j.cgh.2018.10.013.

8. Drossman D, Szigethy E. The narcotic bowel syndrome: a recent update. Am J Gastroenterol Suppl 2014;2:22-30.

9. Naloxegol for opioid-related gastroparesis. 2018. Available from: https://ClinicalTrials.gov/show/NCT03036891 [Accessed 6 May 2019].

10. Barocas JA, White LF, Wang J, et al. Estimated prevalence of opioid use disorder in Massachusetts, 2011-2015: a capture-recapture analysis. Am J Public Health 2018;108:1675-1681.

11. Rudd RA, Seth P, David F, Scholl L. Increases in drug and opioidinvolved overdose deaths - United States, 2010-2015. MMWR Morb Mortal Wkly Rep 2016;65:1445-1452.

12. Weiss AJ, Elixhauser A, Barrett ML, Steiner CA, Bailey MK, O'Malley L. Opioid-related inpatient stays and emergency department visits by state, 2009-2014: statistical brief \#219. Healthcare cost and utilization project (HCUP) statistical briefs. Rockville (MD), 2006.

13. Cohen-Mekelburg S, Rosenblatt R, Gold S, et al. The impact of opioid epidemic trends on hospitalized inflammatory bowel disease patients. J Crohns Colitis 2018 May 7 [Epub ahead of print]. doi: 10.1093/ecco-jcc/jjy062

14. Department of Health and Human Services. The opioid epidemic by the numbers. Available from: https://www.hhs.gov/opioids/ [Accessed 6 May 2019].

15. Hagemeier NE. Introduction to the opioid epidemic: the economic burden on the healthcare system and impact on quality of life. Am J Manag Care 2018;24:S200-S206.

16. Vowles KE, McEntee ML, Julnes PS, Frohe T, Ney JP, van der Goes DN. Rates of opioid misuse, abuse, and addiction in chronic pain: a systematic review and data synthesis. Pain 2015;156:569-576.

17. Florence CS, Zhou C, Luo F, Xu L. The Economic burden of prescription opioid overdose, abuse, and dependence in the United States, 2013. Med Care 2016;54:901-906.

18. Ordookhanian C, Kaloostian PE, Mattei TA. Taming the opioid epidemic: The NIH HEAL initiative. World Neurosurg 2018;120:435-436.

19. U.S. Agency for healthcare research and quality. NIS description of data elements, 2014.

20. Qayed E, Muftah M. Frequency of hospital readmission and care fragmentation in gastroparesis: A nationwide analysis. World $J$ Gastrointest Endosc 2018;10:200-209.

21. Wadhwa V, Mehta D, Jobanputra Y, Lopez R, Thota PN, Sanaka MR. Healthcare utilization and costs associated with gastroparesis. World J Gastroenterol 2017;23:4428-4436.

22. Menendez ME, Neuhaus V, van Dijk CN, Ring D. The Elixhauser comorbidity method outperforms the Charlson index in predicting inpatient death after orthopaedic surgery. Clin Orthop Relat Res 2014;472:2878-2886.

23. Bell TJ, Panchal SJ, Miaskowski C, Bolge SC, Milanova T, Williamson R. The prevalence, severity, and impact of opioidinduced bowel dysfunction: results of a US and European Patient Survey (PROBE 1). Pain Med 2009;10:35-42.

24. Oderda GM, Lake J, Rüdell K, Roland CL, Masters ET. Economic burden of prescription opioid misuse and abuse: a systematic review. J Pain Palliat Care Pharmacother 2015;29:388-400.

25. The White House. Council of Economic Advisers Report: the underestimated cost of the opioid crisis, 2017. Available from: https://www.whitehouse.gov/briefings-statements/cea-reportunderestimated-cost-opioid-crisis/[Accessed 6 May 2019].

26. Birnbaum HG, White AG, Schiller M, Waldman T, Cleveland JM, Roland CL. Societal costs of prescription opioid abuse, dependence, and misuse in the United States. Pain Med 2011;12:657-667.

27. Haycraft AL. Pregnancy and the opioid epidemic. J Psychosoc Nurs Ment Health Serv 2018;56:19-23.

28. Roper V, Cox KJ. Opioid use disorder in pregnancy. J Midwifery Womens Health 2017;62:329-340.

29. Rajmohan V, Kumar SK. Psychiatric morbidity, pain perception, and functional status of chronic pain patients in palliative care. Indian J Palliat Care 2013;19:146-151.

30. Klabunde CN, Warren JL, Legler JM. Assessing comorbidity using claims data: an overview. Med Care 2002;40:IV-26-35.

31. Cooper GS, Chak A, Lloyd LE, Yurchick PJ, Harper DL, Rosenthal GE. The accuracy of diagnosis and procedural codes for patients with upper GI hemorrhage. Gastrointest Endosc 2000;51:423-426. 